\title{
Inspection of $W$ 7-X plasma-facing components after the operation phase OP1.2b: observations and first assessments
}

\author{
C P Dhard ${ }^{1, *}$, S Äkäslompolo, M Balden ${ }^{2}, \mathrm{~J} \mathrm{Baldzuhn}^{1}$, C Biedermann ${ }^{1}$, T Bräuer ${ }^{1}, \mathrm{~S}$ \\ Brezinsek $^{3}$, M Endler ${ }^{1}$, Y Hayashi ${ }^{4}$, D Hwangbo ${ }^{5}$, S Kajita ${ }^{6}$, M Krause ${ }^{1}$, P Kornejew ${ }^{1}$, S

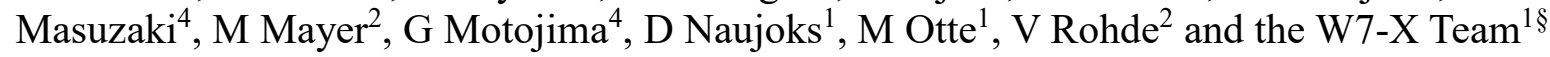 \\ ${ }^{1}$ Max-Planck-Institut für Plasmaphysik, Wendelsteinstrasse 1, 17491 Greifswald, Germany \\ ${ }^{2}$ Max-Plank-Institut für Plasmaphysik, Boltzmannstrasse 2, 85748 Garching, Germany \\ ${ }^{3}$ Forschungszentrum Jülich GmbH, Institut für Energie- und Klimaforschung - Plasmaphysik, Partner of the \\ Trilateral Euregio Cluster (TEC), 52425 Jülich, Germany \\ ${ }^{4}$ National Institute for Fusion Science, 322-6 Oroshi, Toki 509-5292, Japan \\ ${ }^{5}$ Department of Electrical Engineering, Graduate School of Engineering, Nagoya University, Furo-cho, Chikusa, \\ Nagoya 464-8603, Japan \\ ${ }^{6}$ Institute of Materials and Systems for Sustainability, Nagoya University, Furo-cho, Chikusa, Nagoya 464-8603, \\ Japan

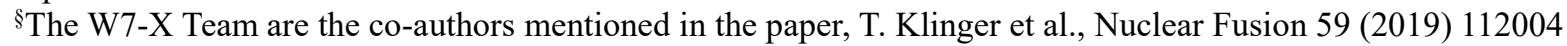

Email: dhard@ipp.mpg.de

Due to its twisted magnetic field configurations, the orientation of the plasma-facing components of the Wendelstein 7-X stellarator is changed from bean shape to triangular shape along the plasma axis within a module. The plasma-facing components consist of graphite (test divertor units, baffles, head shield tiles, toroidal divertor closures) and stainless steel components (wall panels, pumping gap panels, poloidal closures). In order to document the status of these components as well as to get the first footprints of the plasma-wall interactions that occurred during the plasma campaign, a detailed inspection of the whole plasma vessel after the plasma campaign is of vital importance. Such an inspection was carried out after the operation phase OP1.2b completed in October 2018. A number of observations were made, such as, molten stainless steel drops, melting of a long term probe, deposition on steel panels, arc traces, loosely bound particles and deposition stripes on the plasma vessel hidden behind the graphite tiles. In order to understand the possible causes, their implication and steps to avoid some of these problems for the next phase of machine operation, an assessment was made. The melting events should be avoided in the future, the others are due to usual plasma-wall interaction mechanisms and will be monitored after each campaign.

Keywords: Wendelstein 7-X, Plasma-facing components, Plasma-wall interaction, Erosion and deposition, Arcing

\section{Introduction}

Wendelstein 7-X (W7-X) is an optimized three-dimensional helically shaped stellarator with fivefold symmetry designed for steady state plasma operation of up to $30 \mathrm{~min}$. Since the beginning of W7-X operation in 2015, there have been three Operation Phases (OP) completed, namely; OP1.1 (Dec. 2015-March 2016), OP1.2a (Sept. 2017 - Dec. 2017) and OP1.2b (July 2018 - Oct. 2018). Due to the operational constraints, the total integral energy input during these phases was limited to $4 \mathrm{MJ}$ (OP1.1), $80 \mathrm{MJ}$ (OP1.2a) and $200 \mathrm{MJ}$ (OP1.2b). In the beginning of OP1.1 only five inboard graphite limiters were installed as Plasma-Facing Components (PFCs). For OP1.2a the limiters were removed and a number of PFCs made of fine grain graphite were installed such as ten inertially cooled discrete island Test Divertor Units (TDUs), baffles, toroidal divertor closures, wall protection heat shield tiles made of fine grain graphite as well as Stainless Steel (SS) wall \& divertor pumping gap panels and poloidal closures (see fig. 1). In addition, for OP1.2b graphite scraper elements were installed near two TDUs in order to mitigate convective plasma heat loads on the pumping gap panels in certain configurations with the evolution of bootstrap current [1-3]. The whole inboard side is covered with graphite heat shield and baffle tiles, whereas the SS wall panels cover most of the outboard side of the plasma vessel except at certain locations, e.g., the triangular cross section, where the heat shield tiles are installed as well. 
After completion of the plasma campaign OP1.2b, a close inspection of the plasma vessel is of vital importance in order to document unforeseen events as well as obtaining a qualitative picture of the erosion and deposition effects due to Plasma-Wall Interactions (PWI). Understanding these events and implementing steps to avoid them in the next operation phases is necessary for a safe and efficient device operation. A number of such observations were made during this inspection after OP1.2b and are evaluated. The details of these and their analyses are presented in the following sections.

\section{Experimental}

OP $1.2 \mathrm{~b}$ was recently completed with an accumulated plasma duration of $9054 \mathrm{~s}$ with 1256 discharges distributed over four different plasma configurations, namely; standard, high mirror, low iota and high iota with the number of discharges 638,234, 169 and 315, respectively. More details about the plasma operations are reported in ref. [2] and [3] and the references therein. Prior to the first plasma operation, the plasma vessel was baked at $150^{\circ} \mathrm{C}$ for $162 \mathrm{~h}$, the whole baking cycle lasted 265 $\mathrm{h}$ at elevated temperatures. In addition, hydrogen/helium glow discharge cleaning was performed for 11:25 $\mathrm{h}\left(\mathrm{H}_{2}\right.$ 9:35 $\mathrm{h}$ and $\left.\mathrm{He} 1: 50 \mathrm{~h}\right)$ before beginning the plasma operation and for 3:27 $\mathrm{h}\left(\mathrm{H}_{2}\right.$ 1:03 $\mathrm{h}$

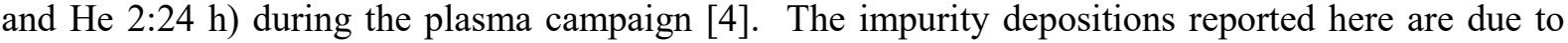
combined effects of the plasma and the glow discharge cleaning operations. During OP1.2b, for the first time in W7-X, three boronizations $\left(90 \% \mathrm{He}+10 \% \mathrm{~B}_{2} \mathrm{H}_{6}\right)$ were performed with four weeks of interval and an accumulated duration of $14 \mathrm{~h}$, which helped in reducing the oxygen content substantially resulting in improved plasma parameters [3].

Elastic Backscattering Spectrometry (EBS) was performed with $2.5 \mathrm{MeV}$ incident protons at normal incidence and a scattering angle of $165^{\circ}$ at the IPP tandem accelerator facility Bombardino using the BesTec manipulator. The beam spot diameter was about $1.8 \mathrm{~mm}$. A Passivated Implanted Planar Silicon (PIPS) detector with $300 \mu \mathrm{m}$ thickness and about $12 \mathrm{keV}$ nominal energy resolution was used [5]. Nuclear Reaction Analysis (NRA) was carried out with incident $2.5 \mathrm{MeV} 3 \mathrm{He}$ ions using the ${ }^{12} \mathrm{C}\left({ }^{3} \mathrm{He}, \mathrm{p} 0\right){ }^{14} \mathrm{~N}$ and ${ }^{10} \mathrm{~B}\left({ }^{3} \mathrm{He}, \mathrm{p} 1\right){ }^{12} \mathrm{C}$ reactions. The experimental spectra were evaluated using the software SIMNRA [6]. Focused Ion Beam (FIB) cutting, Scanning Electron Microscopy (SEM) and Energy-Dispersive X-ray spectroscopy (EDX) measurements were carried out using a FEI "Helios Nanolab 600" and a ZEISS "AURIGA 60" device equipped with analytics from OXFORD and BRUKER at IPP.

An optical reflection measurement technique was employed for the in-situ measurements inside the plasma vessel. By this technique the intensities of reflected Red, Green and Blue (RGB) lights from the measurement spot $(\sim 5 \mathrm{~mm}$ diameter) are measured and together with ellipsometric measurements, the deposited layer thickness is estimated [7]. The whole plasma vessel including its components and the ports were checked for arc traces using a Dino-Lite optical microscope.

\section{Results and discussion}

\subsection{Impurity depositions}

\subsubsection{Plasma vessel wall}

On the whole inboard side plasma vessel wall behind the graphite tiles, sharp deposition stripes were observed, located at the gaps between the tiles as shown in figure 2. These depositions appeared also on a TAG number plate (see fig. 2 inset (a)) incidentally fixed at the stripe location. This was removed and analyzed with EBS. The measured areal densities are shown in table 1. By comparing the values on the base material (\#3) to the stipe regions (\#1 and \#2), the deposited material was found to consist mainly of $\mathrm{C}$ with small amount of $\mathrm{O}$ and traces of $\mathrm{B}(\mathrm{H}$ is not measured by the technique used). Along a line perpendicular to the deposition stripe (see fig. 2 inset (a)), SEM/EDX measurements were done (see figure 3). The EDX measurements are difficult to quantify due to the layered structure, but provide a qualitative confirmation of the EBS results. The deposition in the stripe is constant (as already indicated by the constant color), while the edges of the stripe are relatively sharp with widths of less than $1 \mathrm{~mm}$. Here, compared to the base material (Fe) deposition of $\mathrm{C}$ is seen at both sides of the stripe. With the measured width of the stripes and the known distance between the neighboring stripes, an array was generated for the whole inboard side of plasma vessel (where the stripes were observed) and the fraction of deposited area $\left(3.23 \mathrm{~m}^{2}\right)$ compared to the total 
area $\left(89.9 \mathrm{~m}^{2}\right)$ was estimated. Further, with the measured thickness, the total amount of deposited C $\left(1.39 \times 10^{22}\right.$ atoms $)$ was estimated to be $0.3 \mathrm{~g}$. Deposition is also expected on the sides of the tiles forming the gap through which $\mathrm{C}$ travelled up to the vessel wall. These tiles are presently being investigated.

Table 1. Areal densities of $\mathrm{C}, \mathrm{O}$ and $\mathrm{B}$ atoms measured by EBS in the deposited stripe. Positions \# 1 and \# 2 are at the deposited stripe and \# 3 at the base material, see figure 2(a). Uncertainties are statistical uncertainties due to the number of counts and the background subtraction. In addition a systematic uncertainty due to the uncertainty of the cross-sections of $5 \%$ is assumed.

\begin{tabular}{llll}
\hline Position & $\begin{array}{l}\text { C } \\
\left(\mathrm{x} 10^{15} \text { atoms } / \mathrm{cm}^{2}\right)\end{array}$ & $\begin{array}{l}\text { O } \\
\left(\mathrm{x} 10^{15} \mathrm{atoms} / \mathrm{cm}^{2}\right)\end{array}$ & $\begin{array}{l}\text { B } \\
\left(\mathrm{x} 10^{15} \mathrm{atoms} / \mathrm{cm}^{2}\right)\end{array}$ \\
\hline$\# 1$ & $458 \pm 52$ & $98 \pm 41$ & $76 \pm 25$ \\
$\# 2$ & $407 \pm 51$ & $131 \pm 41$ & $76 \pm 25$ \\
$\# 3$ & $80 \pm 47$ & $61 \pm 41$ & $<20$ \\
\hline
\end{tabular}

\subsubsection{Inner divertor closures}

The space behind the TDUs were closed using $0.5 \mathrm{~mm}$ thin SS plates named as inner divertor closures. When the TDUs were removed for installing the water cooled high heat flux divertors, depositions were seen on these closures. These depositions were analyzed using EBS and NRA. In fig. 4, the plot of EBS/NRA measurements superimposed at the 16 measuring positions on the plate, shows variation of deposited layer thicknesses. A gradient of deposition was observed with peak values of about $2 \times 10^{18}$ atoms $/ \mathrm{cm}^{2}$ for $\mathrm{C}$, the amounts of $\mathrm{O}$ and $\mathrm{B}$ were relatively small. The observed depositions were accumulated during two experimental campaigns, i.e., OP1.2a and OP1.2b. Most likely, these deposits were created during OP1.2a operation mimicking the scraper configurations, when the strike lines were moved close to the pumping gap panels and some of the convective loads could reach the closures. For OP1.2b, however, these loads were blocked by modified graphite baffle tiles (L-shaped tiles) in this region. Further analysis will be carried out to clarify if any deposition took place during OP1.2b as well. Significant footprints of three boronizations were not seen at these interior locations. These closures have been removed, for the next phase of operations, together with the new divertor, new closures will be installed.

\subsubsection{Wall \& pumping gap panels and poloidal closures}

During the inspection, deposits were observed on the SS outer wall panels, on the pumping gap panels installed between the horizontal and vertical part of TDUs and on the poloidal closures. Optical reflection measurements were performed on all the panels around the torus. The thickness profile on the wall panels shows a definitive pattern with the thickest deposition around the interface between the modules and the thinnest in the middle of the modules [8]. One such area of thicker deposition on the wall panels close to the toroidal closure along the torus is visible in fig. 1. From the deposition pattern it is hard to distinguish the differences due to the scraper elements. Depositions were seen only on certain areas of pumping gap panels as well. Interesting deposition patterns were observed on the poloidal closures (see fig. 5), with thicker depositions at the edges, which are located close to the area of thicker depositions on the wall panels (see fig. 1). Different depositions on upper and lower closures of a module indicate up-down asymmetry with the comparatively larger number of panels at the lower poloidal closures experiencing thicker depositions. Such asymmetries were observed in all five modules.

\subsection{Loosely bound particles}

Loosely bound and free particles, flakes etc. provide useful information about the chemistry of PWI processes taking place during plasma operation [9]. Keeping this in mind, once the vessel was accessible, one of the first tasks was to collect these particles avoiding the possibilities of external dust particles entering the vessel. Three different techniques, namely vacuum filters, sticky probes and 
collection by brush, were employed to collect the samples over the whole vessel. Altogether 44 samples were collected. Only small amount of loosely bound particles were found.

The samples were analyzed using SEM/EDX. Fig. 6 shows as an example a C-flake and in fig. 7 the EDX images of a selected area from fig. 6 (a) are given. From the measurements, the observed particles could be mainly classified in three categories: C-dominated flakes, Fe particles with $\mathrm{Cr}$, Ni and $\mathrm{Mn}$ traces and $\mathrm{Al}-\mathrm{Cu}$ particles. $\mathrm{C}$ originates mainly from the erosion of test divertor units and debris of graphite parts and $\mathrm{Fe}, \mathrm{Cr}, \mathrm{Ni}$ and $\mathrm{Mn}$ from the SS panels and structures. $\mathrm{Cu}$ is present in the $\mathrm{Cu}-\mathrm{Cr}-\mathrm{Zr}$ support structure of graphite tiles for the baffles, heat shields and toroidal closures. For $\mathrm{Al}$ the possible sources could be ceramic feedthroughs made from $\mathrm{Al}_{2} \mathrm{O}_{3}$ or glass windows. Since three boronizations were carried out for reducing the $\mathrm{C}$ and $\mathrm{O}$ impurities, it was explored whether boron was present in these samples, however it was found to be below measurable levels.

In the future, after every plasma campaign, such particle samples will be collected and analyzed. Possibilities are being explored to install some of the particle collection boxes at fixed locations similar to the ones installed in ASDEX Upgrade [9].

\subsection{Arcing}

Material erosion due to arcing has been observed in fusion machines e.g. ASDEX Upgrade [10], DIII-D [11], JT60-U and LHD [12]. Such investigations were made after OP1.2b for the first time in W7-X. Altogether 212 positions with arc traces have been found on the panels, ports, plasma vessel and the tile supports. Out of these, 158 were observed on the plasma-facing side and the rest on the back side. Typical arc traces observed on the backside of a panel and an enlarged view of an area with random arc traces with optical microscope are shown in fig. 8 . The length of these traces varies from $1-2 \mathrm{~cm}$ up to about $0.5 \mathrm{~m}$. Only a small fraction i.e. $<10 \%$ of these have been found to follow $-J x B$ direction due to the magnetic field generated by the main superconducting coils. The majority of the tracks are oriented in random directions. Besides, about $25 \%$ of these arcs even occurred on nonplasma-facing sides, indicating the origin of these arcs to be due to the glow discharges. The depth of these traces appears to be very small and no observable material erosion in the form of fine dust was seen around these positions. The observed arc traces were accumulated over the three campaigns, now this investigation will be repeated after every campaign to study the evolution over different operation phases.

\subsection{Melting events}

\subsubsection{Flux surface mapping probe}

One of the probes installed in the plasma vessel in module 1 for the three dimensional magnetic flux surface mapping [1] was retracted into the port during OP1.2b. Despite of this port remaining closed with a shutter, a part of $\varphi 3.0 \times 0.5 \mathrm{~mm}$ SS probe tube was molten and flowed out of the sealed flange through the damaged sealing and drops were falling down as well as spread on the neighboring tiles. The problems probably occurred due to an inappropriate setting of polarization for the Electron Cyclotron Resonance Heating (ECRH) remote launcher. For the future operations this will be corrected by introducing an interlock in the ECRH control software. Furthermore, the shutter and frontend which were uncooled for these operations will be water-cooled in the future.

\subsubsection{Wafer probe holder}

Forty-four pieces of long term deposition probes of three different types, i.e. Si-wafer, directional material and cavity probes $[13,14]$ were installed at the outboard wall as well as at the pumping gap panels in module 4 (see fig. 1) for monitoring depositions on these low power loaded components. One of the edges of a SS probe holding the Si-wafer installed around the mid-plane was found to be molten. All the other probes were intact, despite some of these located on the pumping gap panels, being closer to the plasma. The role of neutral beam injected fast ion orbit losses was investigated for this melting event, using the ASCOT suit of code which has been used to study a range of Neutral Beam Injection (NBI) experiments in W7-X. Details of the simulations are presented in ref. [15]. These simulations covered experiments from the various $\mathrm{W} 7-\mathrm{X}$ plasma configurations enumerated in the beginning of chapter 2 . The simulations utilized accurate experiment geometry for the NBI 
injectors, magnetic field and plasma-facing components and followed NBI injected fast ions from ionization, through the slowing down process, until cooled down to thermal energy or hitting the wall. The simulation results showed, firstly, that only the molten holder received significant heat load from NBI orbit losses, and, secondly, the load was high only in the simulation of the standard configuration [16]. Figure 9 presents results from these simulations, and they are to be perceived as typical values for various NBI experiments during the campaign, not for quantitative assessment of this particular melting event: the investigated plasma shot $\# 20180918.040$ was fueled with $\mathrm{H}_{2}$ and heated with ECRH (5.52 MW) and NBI (1.8 MW). The estimated fast ion heat load at the surfaces of the 44 probes are shown in fig. 9(c), and the maximum load of ca. $180 \mathrm{~W}\left(5 \mathrm{MW} / \mathrm{m}^{2} \times 36 \times 10^{-6} \mathrm{~m}^{2}\right)$ is to the molten probe (fig. 9(a) and (b)) number 10. According to the mass of the molten SS part, this load was sufficient for the observed melting. Except for the probe number 11 with loads around $10 \mathrm{~W}$, on all the other probes the estimated loads are far below $10 \mathrm{~W}$. For future operations, no probe will be installed at this location, besides, in order to account for the plasma operations with reversed magnetic field, another probe at the mirror opposite location will be removed as well.

\section{Summary}

A detailed inspection of the PFCs was carried out after the completion of OP1.2b and a number of observations about melting, depositions, arcing and loosely bound particles were made. A small part of the eroded $48 \mathrm{~g} \mathrm{C}$ from the divertor strike line positions [5] was found to be deposited on the vessel wall, inner divertor closures and the panels. From the estimated small amount of depositions it is still difficult to establish the $\mathrm{C}$ balance, for which the investigation of a large number of tiles and the estimation of the pumped out fractions through the vacuum pumps would be necessary, which is presently ongoing.

For future operations, such inspections will be carried out after every campaign. The observed melting events will be avoided by implementing safety interlocks at the ECRH remote launchers and removing the probes from the locations where higher fast ion loads are expected. For the next operation phase, the inertially cooled test divertor units will be replaced with the water cooled carbon fiber composite high heat flux divertor, cryo-vacuum pumps will be installed behind the divertors and water cooling for all the PFCs is foreseen. This will have an impact on the PFCs operating temperatures and neutral pressures in the divertor region leading to some changes in the erosion/deposition patterns which will then be observed during the inspection.

\section{Acknowledgments}

This work has been carried out within the framework of the EUROfusion Consortium and has received funding from the Euratom research and training programme 2014-2018 and 2019-2020 under grant agreement No 633053. The views and opinions expressed herein do not necessarily reflect those of the European Commission.

\section{References}

[1] Sunn Pedersen T, Otte M, Lazerson S, Helander P, Bozhenkov S, Biedermann C, Klinger T, Wolf R $\mathrm{C}$, Bosch H -S and the Wendelstein 7-X Team 2016 Confirmation of the Topology of the Wendelstein 7-X Magnetic Field to Better than 1:100,000 Nature Communications 713493.

[2] Sunn Pedersen T et al 2019 First Results from Divertor Operation in Wendelstein 7-X Plasma Phys. Controlled Fusion 61014035

[3] Klinger T et al 2019 Overview of first Wendelstein 7-X high performance operation Nucl. Fusion 59 112004

[4] Brezinsek S et al 2019 Introduction to TG Plasma-Wall Interaction Session, W7-X Workshop May 14-17 Greifswald, Germany

[5] Mayer M et al 2019 Material erosion and deposition on the divertor of W7-X, Physica Scripta submitted

[6] Mayer M 1997 SIMNRA User's Guide Tech. rep. IPP 9/113 Garching, Max-Planck-Institut für 
Plasmaphysik, url: https://home.mpcdf.mpg.de/ mam/Report\%20IPP\%209-113.pdf

[7] Motojima G et al 2017 Wide-range evaluation of the deposition layer thickness distribution on the first wall by reflection coefficient measurements, Nucl. Mater. Energy 12 1219-1223

[8] Motojima G et al 2019 In-vessel colorimetry of Wendelstein 7-X first wall components: Variation of the layer deposition distribution in OP1.2a and OP1.2b, Physica Scripta submitted

[9] Balden $\mathrm{M}$ et al 2014 Collection strategy, inner morphology, and size distribution of dust particles in ASDEX Upgrade Nucl. Fusion 54073010

[10] Rohde V et al 2011 Tungsten erosion by arcs in ASDEX upgrade, J Nucl. Mat. $415 \mathrm{~S} 46$

[11] Bykov I et al 2017 Tungsten erosion by unipolar arcing in DIII-D, Phys. Scr. T170 014034

[12] Kajita S et al 2013 Impact of arcing on carbon and tungsten: from the observations in JT-60U, LHD and NAGDIS-II Nucl. Fusion 53053013

[13] Dhard C P et al 2017 Preparation of erosion and deposition investigations on plasma facing components in Wendelstein 7-X Phys. Scr. T170 014010

[14] Dhard C P et al 2019 Erosion and deposition investigations on Wendelstein 7-X first wall components for the first phase in divertor configuration Fusion Eng. Des. 146242

[15] Äkäslompolo S et al 2018, Modelling of NBI ion wall loads in the W7-X stellarator Nucl. Fusion 58 082010

[16] Äkäslompolo S et al 2019, Validating the ASCOT modeling of NBI fast ions in Wendelstein 7-X, accepted for publication in Journal of Instrumentation, arXiv:1906.07457 [physics.plasm-ph]. 


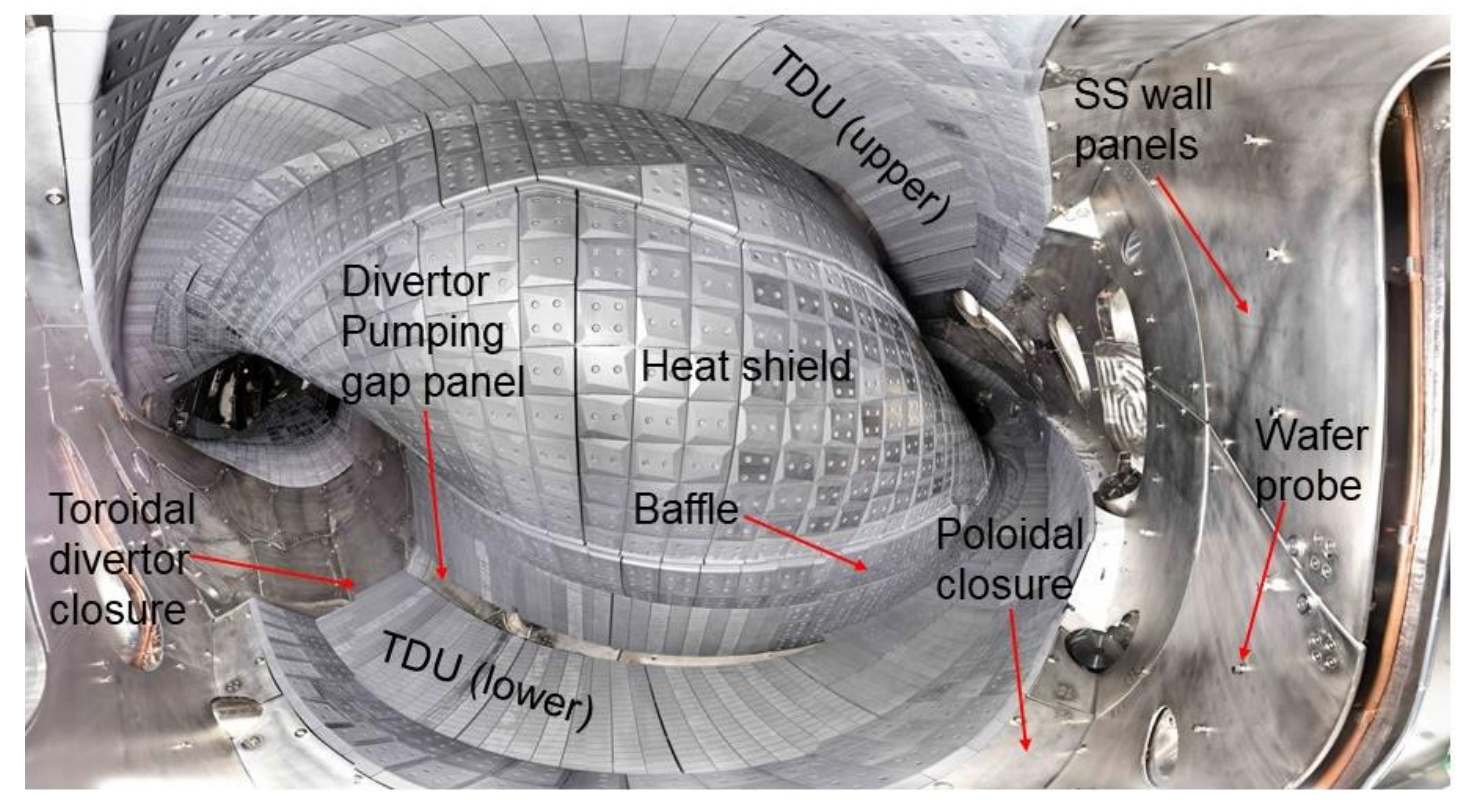

Figure 1. Panorama view into the W7-X plasma vessel from W7-X module 4, showing the installed plasma-facing components.

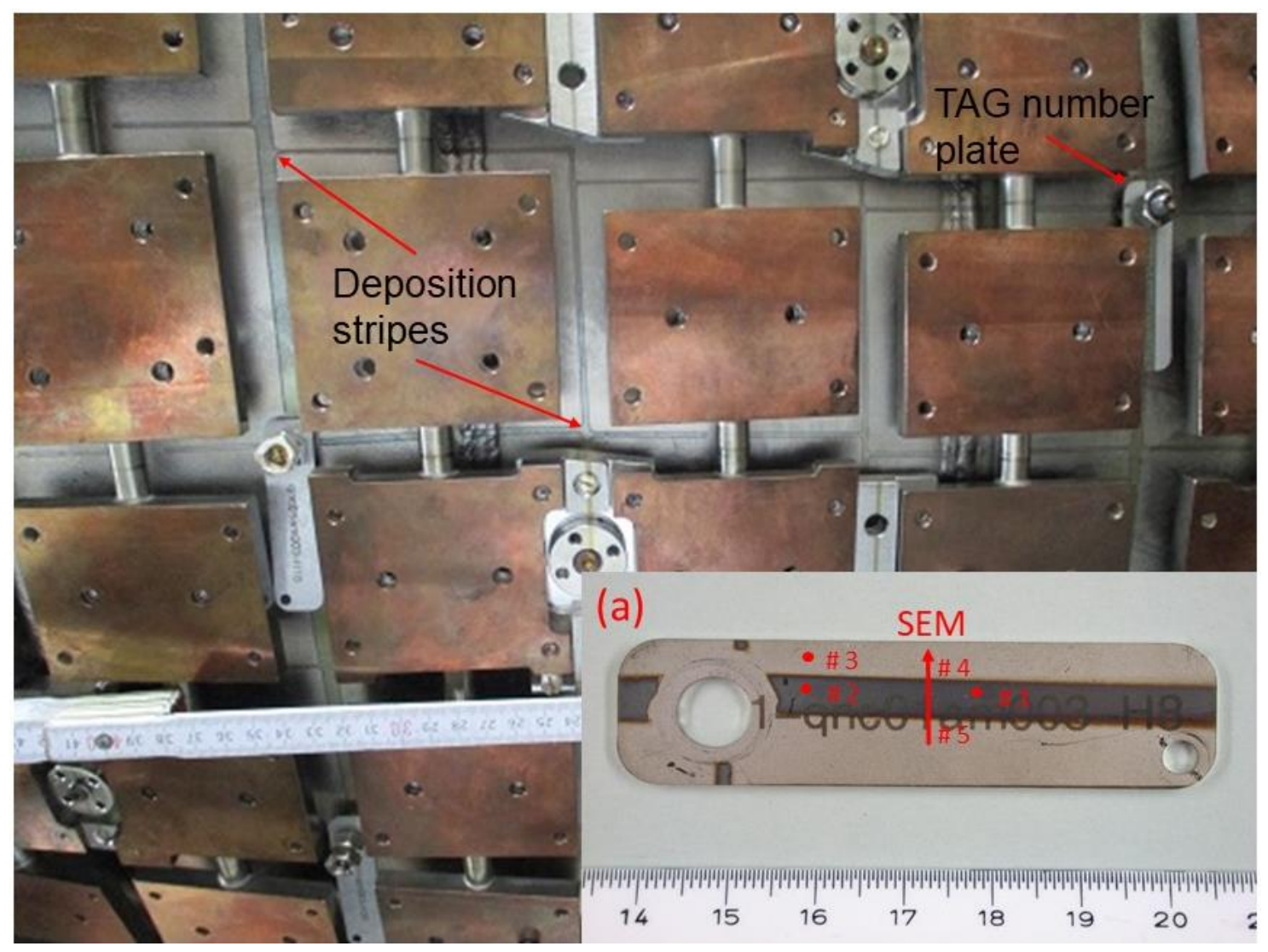

Figure 2. View of the inboard side plasma vessel showing the $\mathrm{Cu}-\mathrm{Cr}-\mathrm{Zr}$ support plates after removing the graphite tiles installed on these plates. The deposition stripes on the vessel wall are visible behind the support plates, inset (a) shows a TAG number plate installed on the vessel on which the stripes were also deposited. Results for the numbered measuring positions are given in table 1 and fig. 3 . 


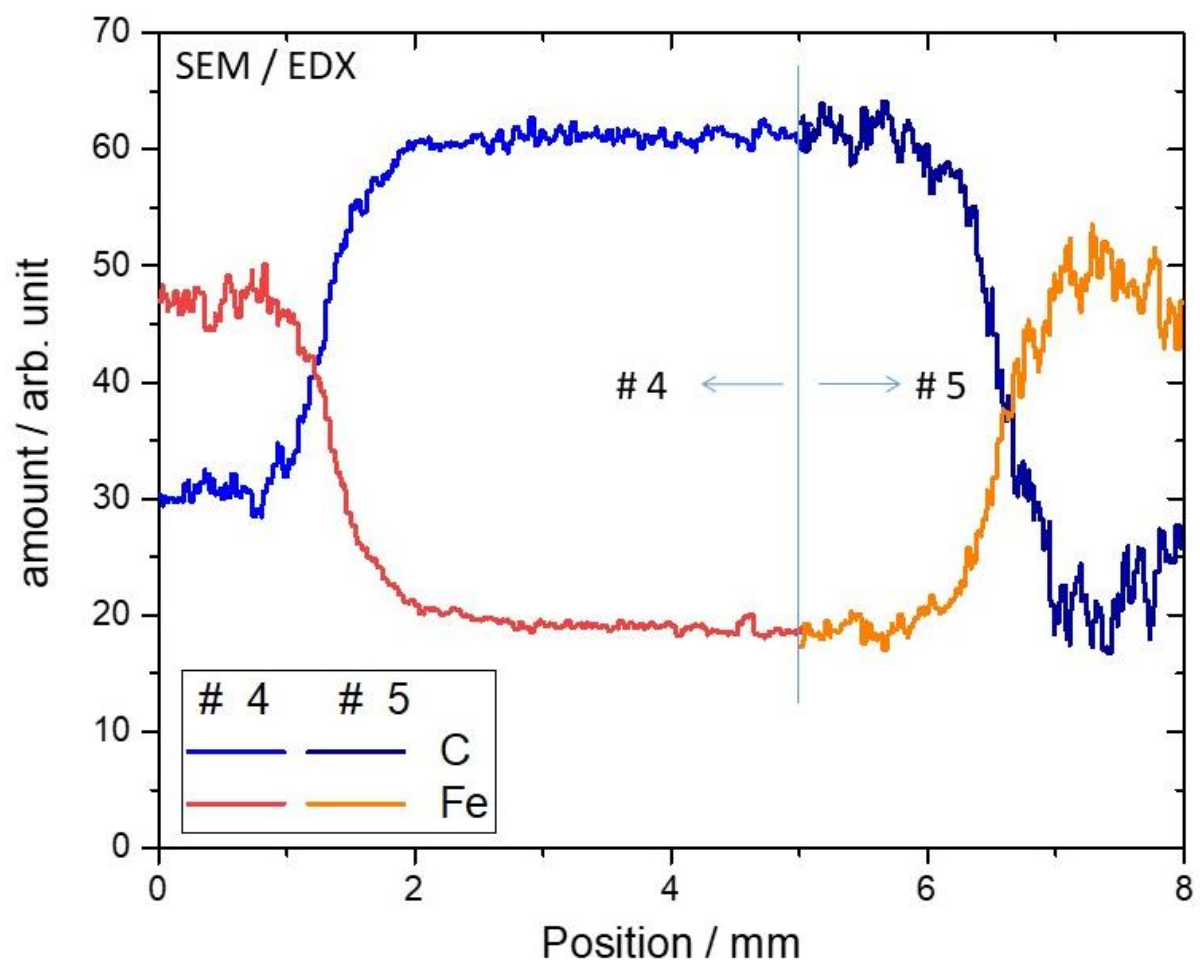

Figure 3. SEM/EDX measurements on the TAG number plate at the line crossing the deposition stripe at the locations \# 4 and \# 5 shown in figure 2 showing the thickness homogeneity and the sharpness of the stripe edges.

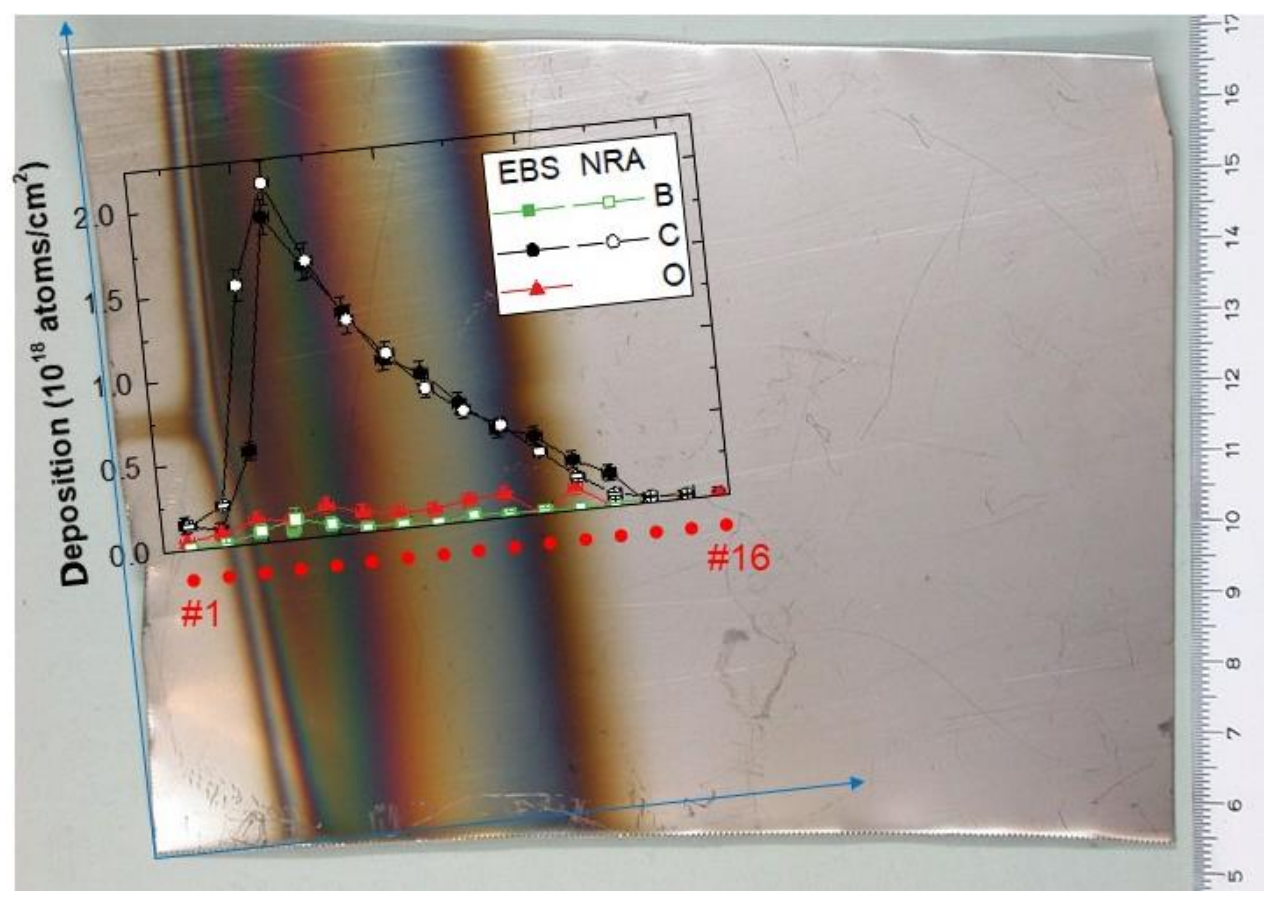

Figure 4. Inner divertor closure plate removed after OP1.2b from the lower TDU in module-2. Deposition layers are visible on the left side of the plate. The plot of EBS/NRA measurements superimposed at the 16 measuring positions (red dots) on the plate, shows variation of deposited layer thicknesses. 

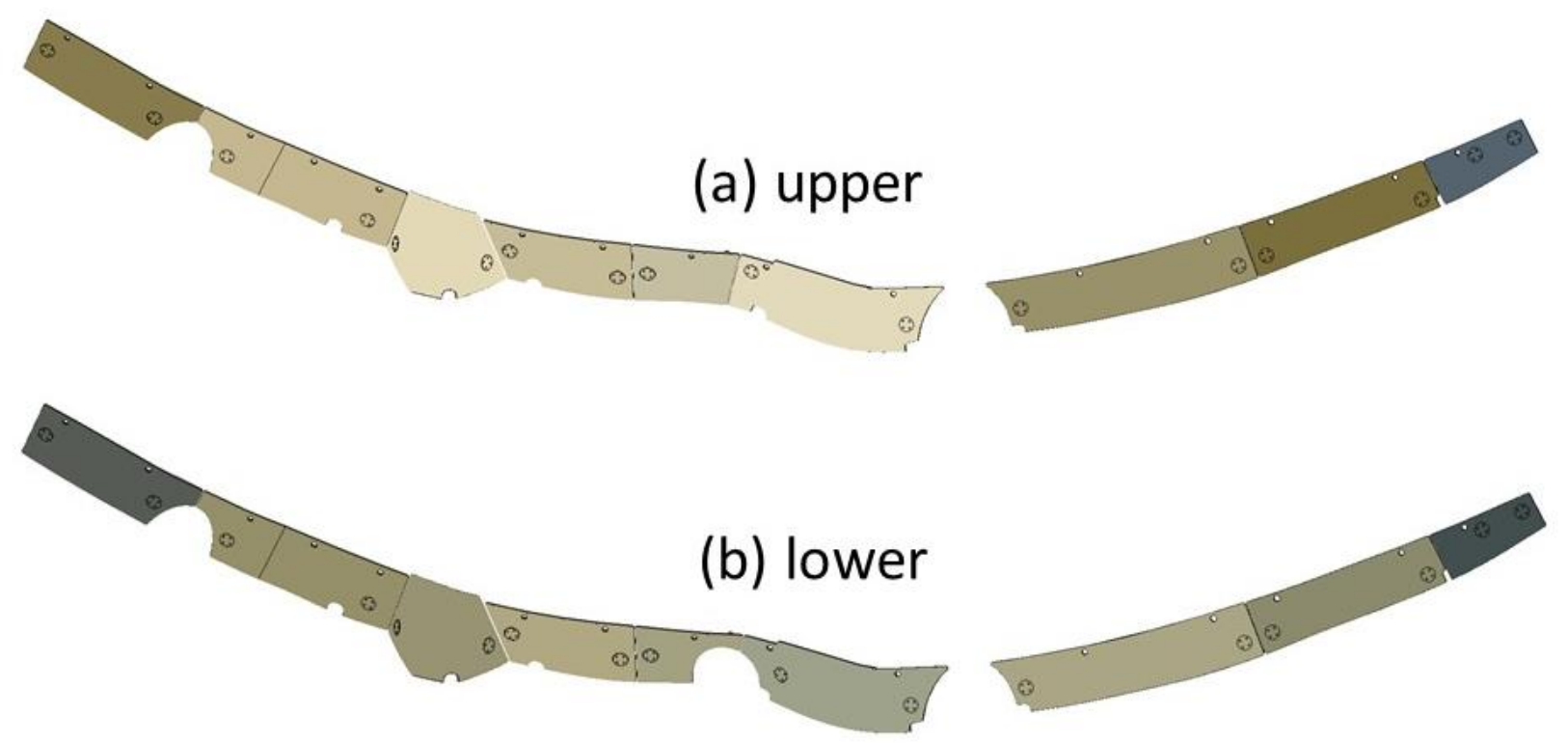

Figure 5. Views of the upper (a) and lower (b) poloidal closures from module 4. The difference in colors of both indicates the up down asymmetry of the depositions.
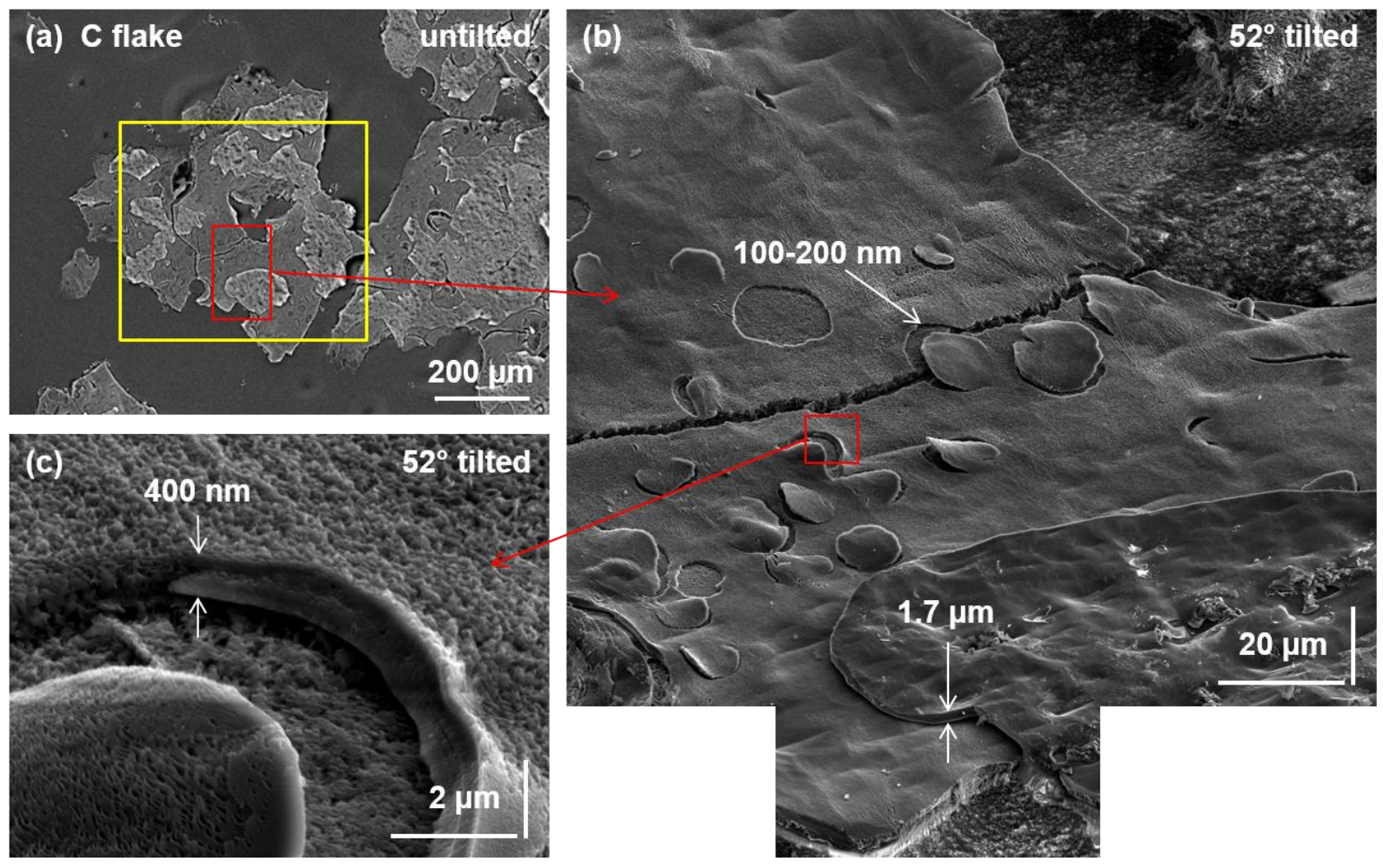

Figure 6. SEM images of a C-flake sample collected from a tile with increasing magnification from (a) to (c). (a) is plain view and (b) and (c) are tilted by $52^{\circ}$. Layered structure with the thickness of layers, e.g., 100-200 nm, $400 \mathrm{~nm}$ and $1.7 \mu \mathrm{m}$ are shown in (b) and (c). EDX images of the area marked by the yellow rectangle in (a) is shown in fig. 7. 

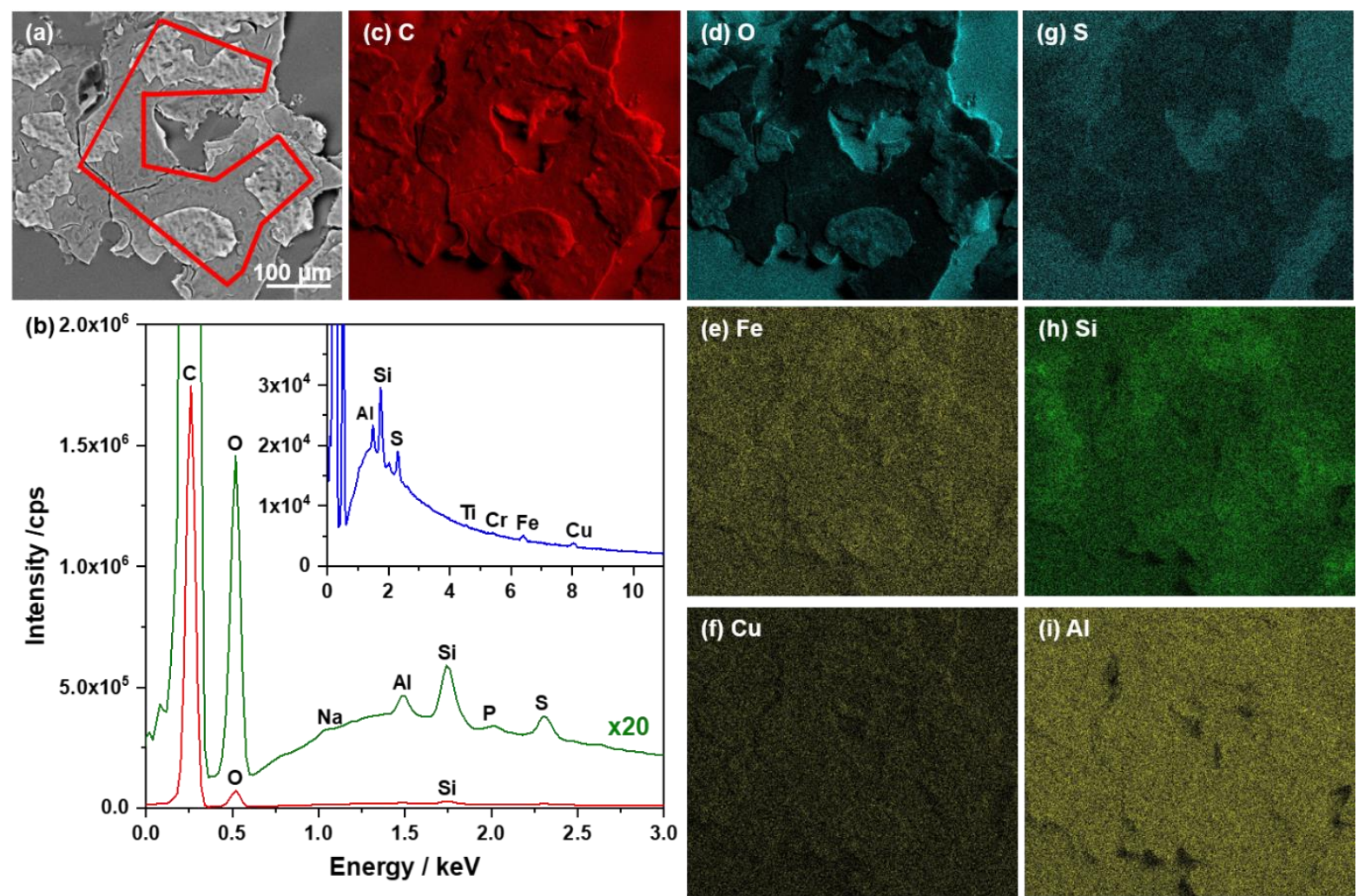

Figure 7. EDX analysis of C-flakes from the area shown in fig. 6 (a) marked by the yellow rectangle there. (a) SEM image recorded with backscatter detector; (b) EDX spectrum of marked area in (a) in different scalings; (c) - (i) EDX intensity maps of various elements after background removal and peak deconvolution. The $\mathrm{C}$-flakes contain partly $\mathrm{O}$ and $\mathrm{Si}$ and traces of metals $(\mathrm{Fe}, \mathrm{Cu}, \mathrm{Al}$ ), while the $\mathrm{S}$ and the $\mathrm{Na}$ (not shown as maps) originated from the glue of the sticky probe.
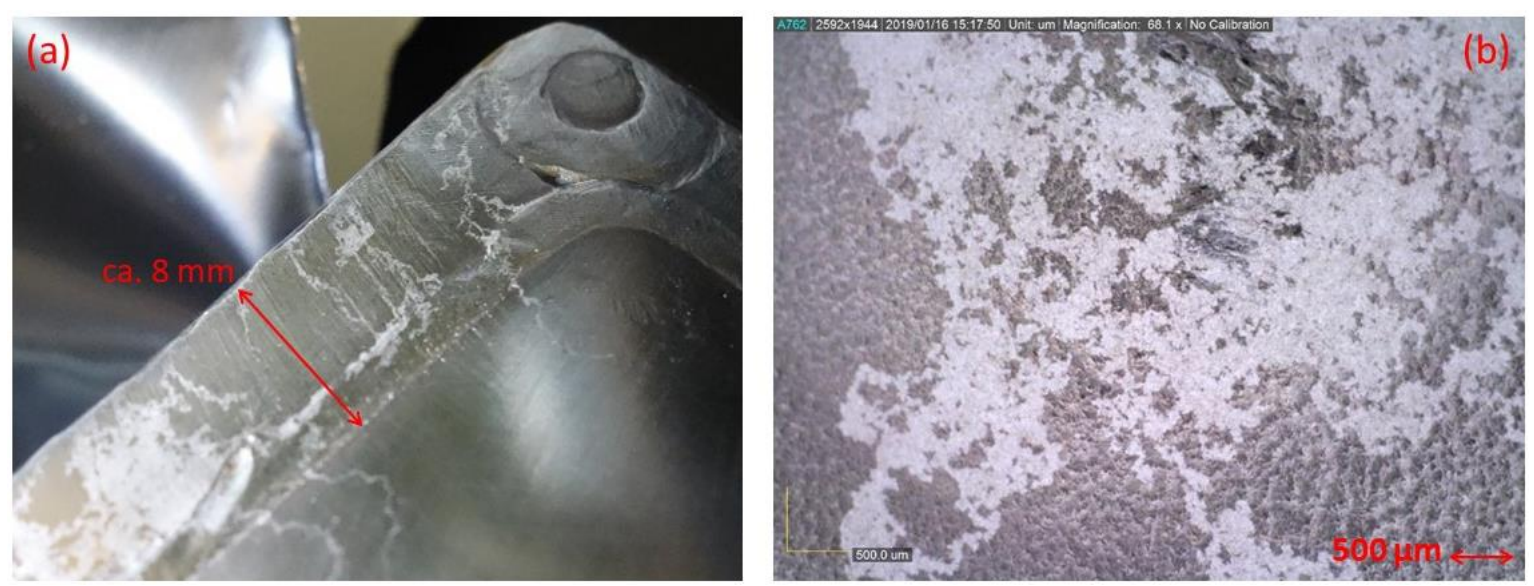

Figure 8. Typical arc trace observed on the backside of a panel (a) and an enlarged view of a random arc trace taken with an optical microscope (b). 


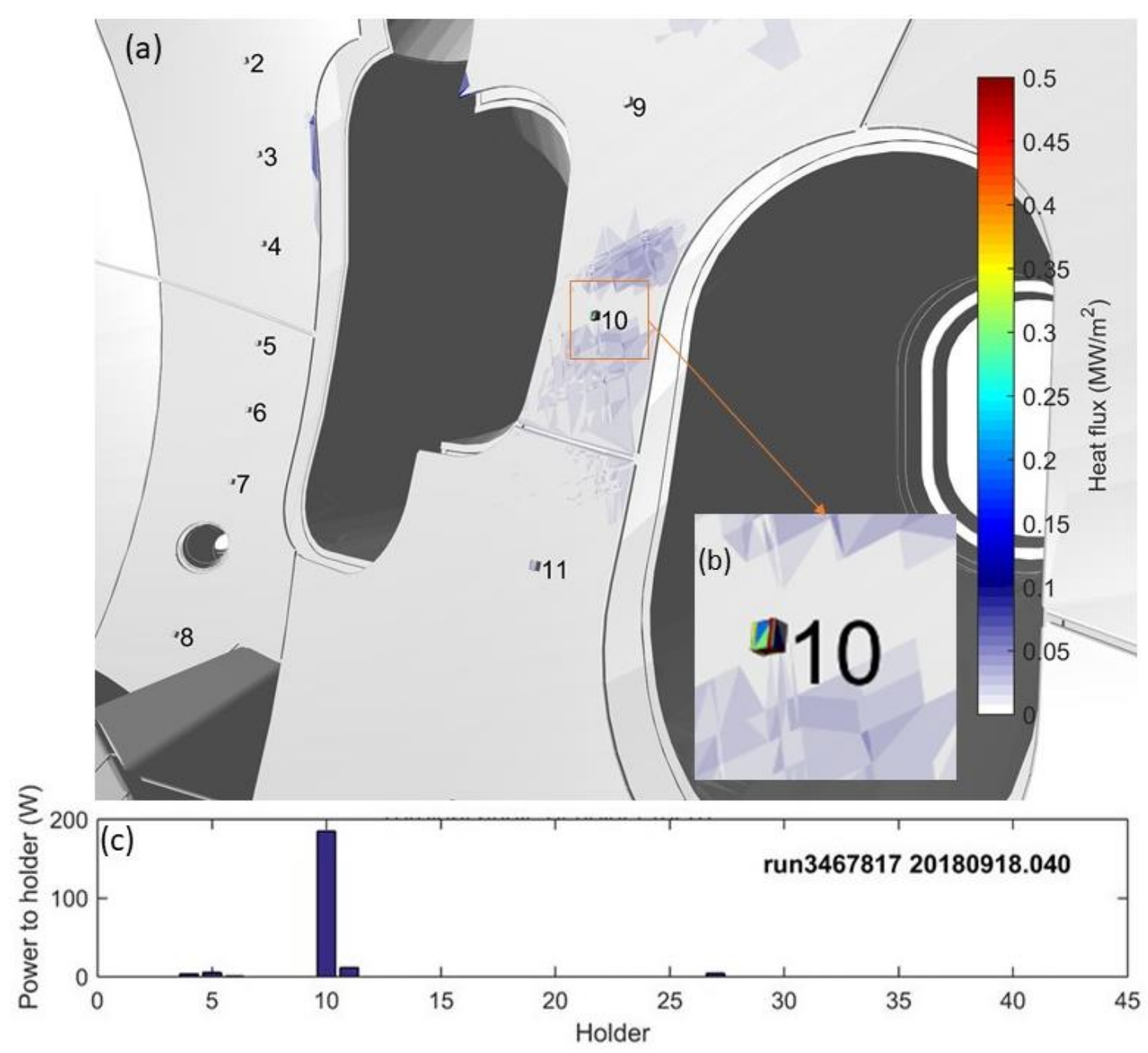

Figure 9. (a) Estimations from the ASCOT code for the NBI fast ion orbit loss heat loads on the wall panels of module 4. The locations of some of the wafer probes, including the location 10 obtaining the highest load, are shown. (b) Enlarged view of the wafer probe number 10 marked with orange rectangle in (a). (c) Estimated fast ion heat load profile on all the 44 wafer probes are shown. The molten probe holder (number 10) received maximum loads around $180 \mathrm{~W}$. 